

\title{
VIBRATION ANALYSIS OF APS MAGNET/SUPPORT SYSTEMS BASED ON THE FINITE ELEMENT METHOD
}

\author{
bj' \\ S. S. Chen and M. W. Wambsganss \\ Materials and Components Technology Division \\ Argonne National Laboratory$$
\text { Alre } 2909
$$

Prediction of the dynamic response of APS magnet/support systems requires knowledge of the free vibrational characteristics, including natural frequencies, modes, and modal damping ratios. A preliminary dynamic analysis of the magnet/support system of a typical section of the APS storage ring, as presented in the APS Conceptual Design Report [1], was performed to yain insight [2]. The preliminary analysis is based on the assumption that the support girder could be considered rigid relative to the stiffness of the pedestal supports when considering the lower modes and frequencies. Further, only the vertical (in-plane) translational and rocking modes were studied. The subject analysis was performed to include the flexibility of the support girder and to investigate the horizontal (out-of-plane) modes as well. Also, the most up-to-date design of the five magnet sections are studied. Here, it should be noted that in the latest design the positioning of the support pedestals (jack-screws) is different from that in the conceptual design.

Five different magnet sections are included in each of the 40 sectors comprising the storage ring. The latest design drawings, magnet weights, and dimensions were obtained for each of the five different sections [3]; see Table 1. Vibration analyses were performed using the computer code, MSC/pal. This is a finite element code to solve for the displacements and stresses of two- and three-dimensional structural and mechanical systems.

All five magnet sections are modelled as discrete systems; as an example, Section 3 is illustrated in Fig. 1. The following assumptions are used in the analyses:

1. The girders are treated as uniform Bernoulli-Euler beams.

2. All magnets are considared as concentrated masses; their rotatory inertias are igriored.

3. The pedestal supports are considered as elastic springs with spring constants estimated from static beam theory; see Appendix.

4. All motions are small. 


\section{DISCLAIMEK}

This report was prepared as an account of work sponsored by an agency of the United States Government. Neither the United States Government nor any agcincy thereof, nor any of their employees, makes any warranty, express or implied, or assumes any legal liability or responsibility for the accuracy, completeness, or usefulness of any information, apparatus, product, or process disclosed, or represents that its use would not infringe privately owned rights. Reference herein to any specific commercial product, process, or service by trade name, trademark, manufacturer, or otherwise does not necessarily constitute or imply its endorsement, recommendation, or favoring by the United States Government or any agency thereof. The views and opinions of authors expressed herein do not necessarily state or reflect those of the United States Government or any agency thereof. 
Each beam element has six degrees of freedom with three translations and three rotations, each mass has three translations only. In each section, approximately 40 to 50 degrees of freedom are considered in the analyses. The vibration of the magnet/support systems can be divided into two motion types: in-plane (vertical) motion in $x-y$ plane and out-of-plane (horizontal) motion in $x-z$ plane. Vibrations in the two planes are not coupled.

Figures 2 through 6 show the first 12 modes, 6 for in-plane motion and 6 for out-of-plane motion. Several general characteristics are noted:

1. Free vibrational characteristics for the five sections are similar.

2. The loweit natural frequency of all five sections is associated with the same mode: the girder rotates about the $y$-axis and the two exterior pedestal supports move out of phase. In this mode, the girder responds predominantly as a rigid beam; the majority of the strain energy is associated with the pedestal supports.

3. The lowest natural frequency of in-plane modes is about 64 $\mathrm{Hz}$, which is much higher than the frequencies of the first two modes of out-of-plane motion.

4. Of the five sections, Section 3 possesses the lowest group of natural frequencies.

Figure 7 shows the first five natural frequencies of Sections 1 to 5 . It is apparent th-t only the first two frequencies of out-of-plane modes are below $25 \mathrm{~Hz}$. All other natural frequencies are considerably higher.

It should be pointed out that there are other in-plane modes predominantly associated with axial oscillation of the girders. These modes have also been calculated. For example, the first three modes for Section 3 are $14.2 \mathrm{~Hz}, 344 \mathrm{~Hz}$, and $668 \mathrm{~Hz}$. The fundamental natural frequency of axial vibration is practically the same as that of the second mode of out-of-plane motion and this is the only mode which may be of concern.

The accuracy of the predicted natural frequencies depends on the validity of the assumptions used in the analysis. Based on the results, several observations can be made: 
a. The girders are relatively short, with the smallest length-to-depth ratio of 4.4. With respect to the first two out-of-plane modes, the girder deformation is not important. Therefore, using Bernoulli-Euler beam theory will not result in any significant error.

b. The rotatory inertias of the magnets are not considered in the analysis. In the first two out-of-plane modes, translational motion of the magnets is much more important than rotation. R statory inertias are not expected to have any major effect.

c. In determining the response in the first two modes, the most important parameter is the stiffness of the pedestal supports. In the analyses, the stiffnesses of the supports are modelled as elastic springs. However, it is important to note that the associated spring constants are difficult to predict accurately.

From these observations, it is apparent that the stiffnesses of the pedestal supports play the dominant role in determining the first two ratural frequencies. Consequently, a study of the natural frequencies with the pedestal support stiffness in the out-of-plane direction as a variable, is performed. Figure 8 shows the first three natural frequencies as a function of the spring constant. The first two modes are associated with out-of-plane motion and the third mode is in-plane motion. For the results given in Figs. 2-6, the spring constant in the out-of-plane direction is estimated to be $2.4 \times 10^{6} \mathrm{~kg} / \mathrm{m}$. In reality, it is expected to be in the range between $10^{6} \mathrm{~kg} / \mathrm{m}$ to $10^{7} \mathrm{~kg} / \mathrm{m}$ depending on the detailed design of the periestal supports and the method of attachment to the foundation.

From Fig. 8 it is noted that the first two natural frequencies are approximately proportional to the square root of the spring constant. If it is necessary to increase the first two natural frequencies without changing other parameters, one can increase the stiffness of the pedestal supports and the frequencies can be calculated easily.

The fact that the analyses show that the deformation of the girder does not affect the two lowest modes for both vertical and horizontal excitation is significant. The significance stems from the fact that this implies that the systems can be analyzed using the simplifieu models employed in Ref. 2 which lend themselves to parameter studies, for example, relative to the effect of pedestal support location on natural frequencies and modes. 
In the analyses, the modal damping values are not included as they are difficult to predict accurately. It is recommended that a mock-up of the magnet/support system, including actual pedestal supports with jack-screws, be tested to measure the stiffnesses of the pedestal supports and to evaluate the damping values.

The natural frequencies and modes provide the necessary information for an initial assessment of the dynamic behavior of the magnet/support systems of the various magnet sections. When other information, such as modal damping values and actual pedestal support stiffnesses, becomes available form prototypic testing, system response to steady-state as well as transient excitation can be calculated.

\section{References}

1. 7-GeV Advanced Photon Source Conceptual Design Report, ANL-87-15, April 1987

2. Wambsganss, M. W., "Preliminary Dynamic Analysis of Conceptual Design of Magnet/Support System for the APS Storage Ring", APS/IN/ VIB/89-2, 6/17/88, Rev. 5/8/89

3. Wehrle, R. B. and Choi, M., Personal Communication, February 20, 1989 
Table 1 Magnet Section Component Weights and Locations of Centers of Mass The locations are with reference to the coordinate system given below -

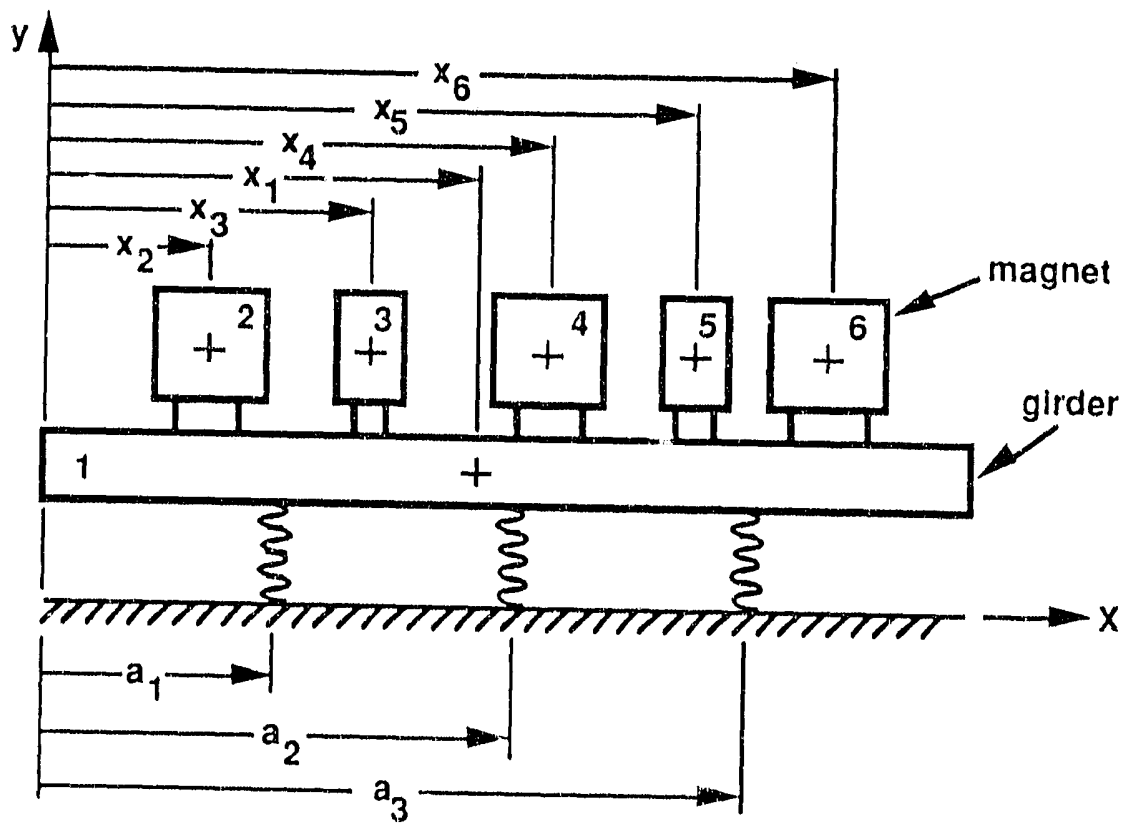

Magnet

Section

$k$ Component $M_{k}(k g) \quad x_{k}(m) \quad y_{k}(m)$

\begin{tabular}{lllrrr}
1 & 1 & Girder & 488 & 1.63 & 0.82 \\
$a_{1}=0.64 \mathrm{~m}$ & 2 & Magnet - Q1 & 1730 & 0.50 & 1.50 \\
$\mathrm{a}_{2}=1.58 \mathrm{~m}$ & 3 & Magnet & 22 & 1.27 & 1.50 \\
$\mathrm{a}_{3}=2.51 \mathrm{~m}$ & 5 & Magnet - Q2 & 2723 & 1.81 & 1.50 \\
& 5 & Magnet - S1 & 580 & 2.49 & 1.50 \\
& 6 & Magnet - Q3 & 1730 & 3.02 & 1.50 \\
\hline
\end{tabular}

$\begin{array}{cllrll}2 & 1 & \text { Girder } & 1207 & 2.40 & 0.88 \\ & 2 & \text { Magnet }-\mathrm{C} 3 & 22 & 0.13 & 1.50 \\ \mathrm{a}_{1}=1.04 \mathrm{~m} & 3 & \text { Magnet }-\mathrm{S} 2 & 580 & 0.43 & 1.50 \\ \mathrm{a}_{2}=2.26 \mathrm{~m} & 4 & \text { Magnet }- \text { M1 } & 5130 & 2.26 & 1.50 \\ \mathrm{a}_{3}=3.48 \mathrm{~m} & 5 & \text { Magnet }-\mathrm{SD} & 580 & 4.09 & 1.50\end{array}$




\begin{tabular}{|c|c|c|c|c|c|}
\hline \multirow[t]{2}{*}{3} & 1 & Girder & 631 & 2.15 & 0.82 \\
\hline & 2 & Magnet - Q4 & 1730 & 0.38 & 1.50 \\
\hline $\mathrm{a}_{1}=0.90 \mathrm{~m}$ & 3 & Magnet & 22 & 0.92 & 1.50 \\
\hline $\mathrm{a}_{2}=1.89 \mathrm{~m}$ & 4 & Magnet - Q5 & 2061 & 1.30 & 1.50 \\
\hline \multirow[t]{4}{*}{$a_{3}=2.87 \mathrm{~m}$} & 5 & Magnet - S1 & 580 & 1.95 & 1.50 \\
\hline & 6 & Magnet - Q5 & 2061 & 2.60 & 1.50 \\
\hline & 7 & Magnet & 22 & 3.05 & 1.50 \\
\hline & 8 & Magnet - Q4 & 1730 & 3.52 & 1.50 \\
\hline \multirow[t]{2}{*}{4} & 1 & Girder. & 1205 & 2.41 & 0.88 \\
\hline & 2 & Magnet - SD & 580 & 0.40 & 1.50 \\
\hline$a_{1}=1.03 \mathrm{~m}$ & 3 & Magnet-M2 & 5130 & 2.24 & 1.50 \\
\hline $\mathrm{a}_{2}=2.24 \mathrm{~m}$ & 4 & Magnet & 580 & 4.09 & 1.50 \\
\hline$a_{3}=3.46 \mathrm{~m}$ & 5 & Magnet & 22 & 4.39 & 1.50 \\
\hline \multirow[t]{2}{*}{5} & 1 & Girder & 465 & 1.71 & 0.82 \\
\hline & 2 & Magnet - Q3 & 1730 & 0.33 & 1.50 \\
\hline$a_{1}=0.72 m$ & 3 & Magnet - S1 & 580 & 0.86 & 1.50 \\
\hline$a_{2}=1.71 \mathrm{~m}$ & 4 & Magnet - Q2 & 2723 & 1.54 & 1.50 \\
\hline \multirow[t]{2}{*}{$a_{3}=2.70 \mathrm{~m}$} & 5 & Magnet & 22 & 2.08 & 1.50 \\
\hline & 6 & Magnet - Q1 & 1730 & 2.85 & 1.50 \\
\hline
\end{tabular}




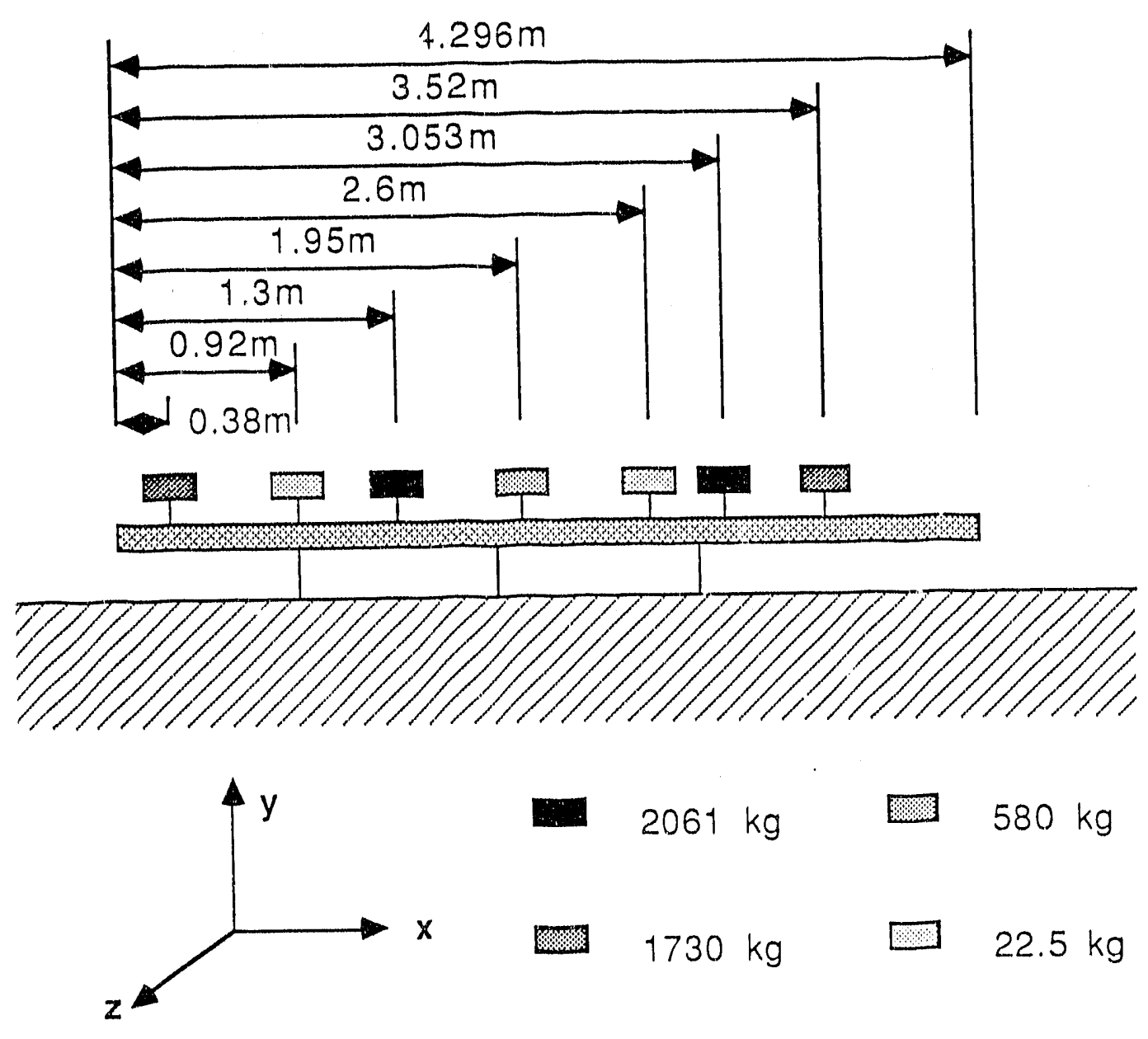

Fig. 1. Discrete Model for Section 3 
5

\section{OUT-OF-PLANE MODES}

$11.9 \mathrm{~Hz}$

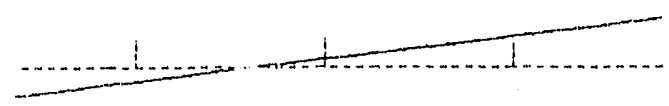

$586.9 \mathrm{HZ}$

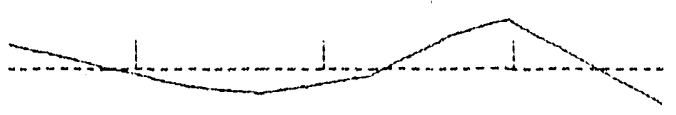

$1126 \mathrm{~Hz}$

$17.1 \mathrm{HZ}$

$120.5 \mathrm{HZ}$

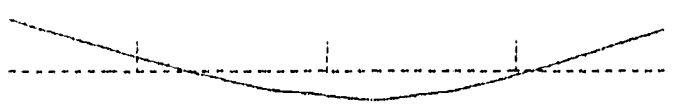

$1973 \mathrm{HZ}$

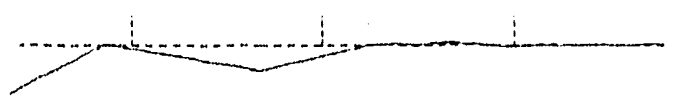

Fig. 2a. Section 1 
IN-PLANE MODES

$76.5 \mathrm{HZ}$

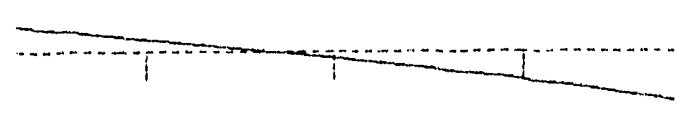

$112.8 \mathrm{HZ}$

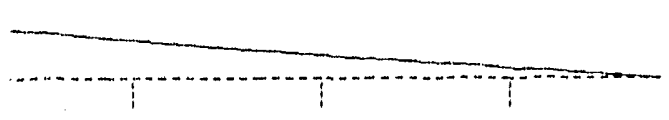

$235 \mathrm{HZ}$

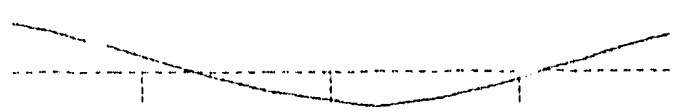

855 HZ

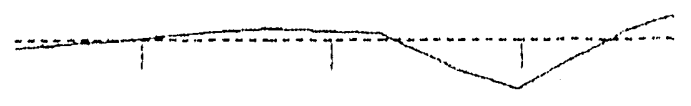

$1611 \mathrm{HZ}$

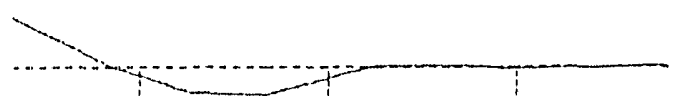

$2433 \mathrm{HZ}$

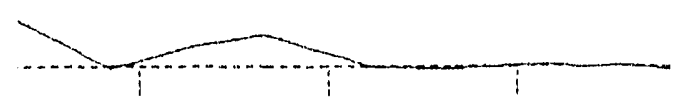

Fig. 2b. Section 1 


\section{7 \\ OUT-OF-PLANE MODES}

$12.8 \mathrm{HZ}$

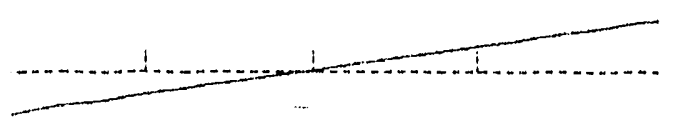

$15.4 \mathrm{HZ}$

$144.9 \mathrm{HZ}$

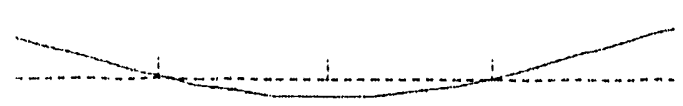

$257.7 \mathrm{HZ}$

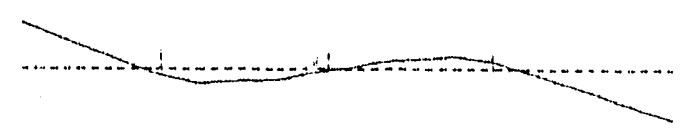

$958.5 \mathrm{~Hz}$

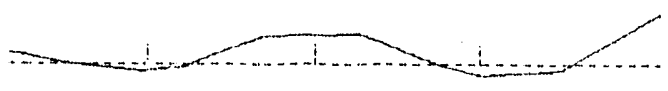

Fig. 3a. Section 2

$1150 \mathrm{~Hz}$

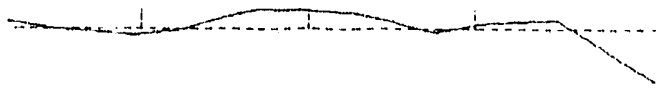


8

IN-PLANE MODES

83.7 HZ

$401.7 \mathrm{HZ}$
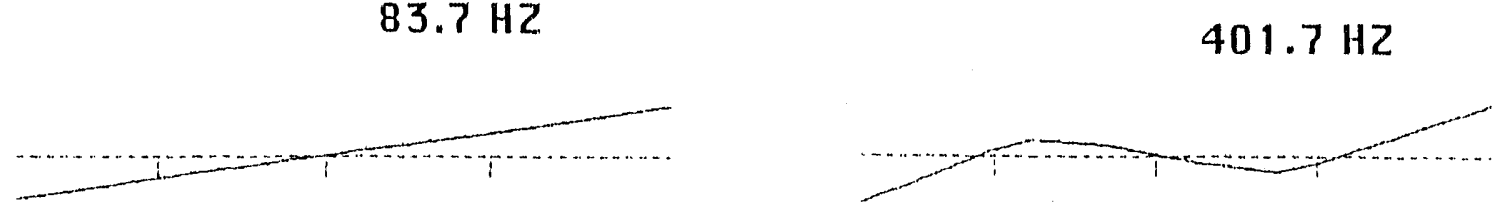

$99.6 \mathrm{HZ}$

$1419 \mathrm{HZ}$

$260.3 \mathrm{HZ}$

$1514 \mathrm{~Hz}$

Fig. 3b. Section 2 


\section{OUT-OF-PLANE MODES}

$10.1 \mathrm{HZ}$

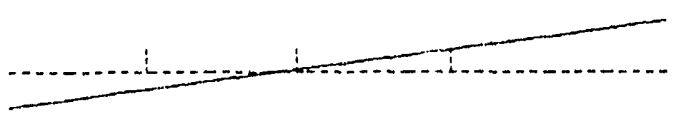

$14.3 \mathrm{HZ}$

$91.9 \mathrm{HZ}$

fig. Ae. Section 3
$218.8 \mathrm{HZ}$

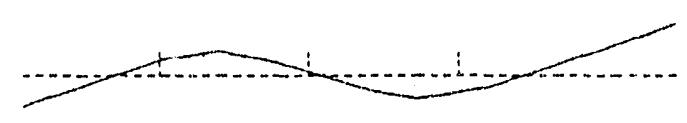

$623 \mathrm{HZ}$

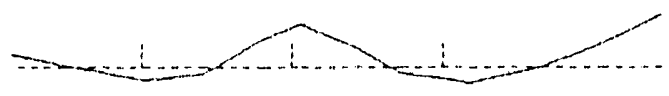

$834 \mathrm{HZ}$

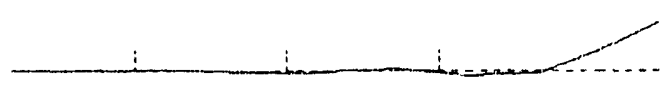


IN-PLANE MODES

$64.3 \mathrm{HZ}$

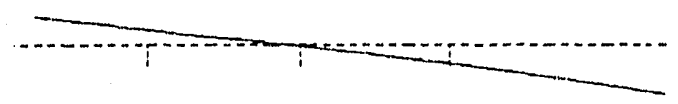

$89.6 \mathrm{HZ}$

$190 \mathrm{HZ}$

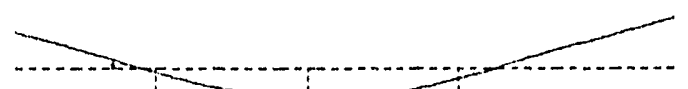

$359 \mathrm{HZ}$

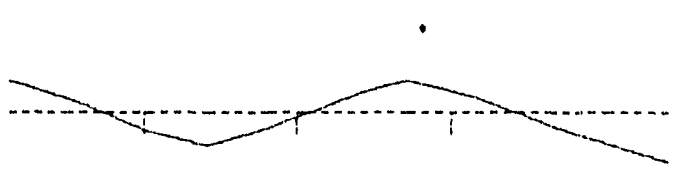

$866 \mathrm{HZ}$

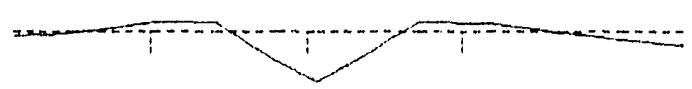

$1206 \mathrm{HZ}$

Fig. 4b. Section 3 
OUT-OF-PLANE MODES

$12.7 \mathrm{HZ}$

$255.9 \mathrm{HZ}$
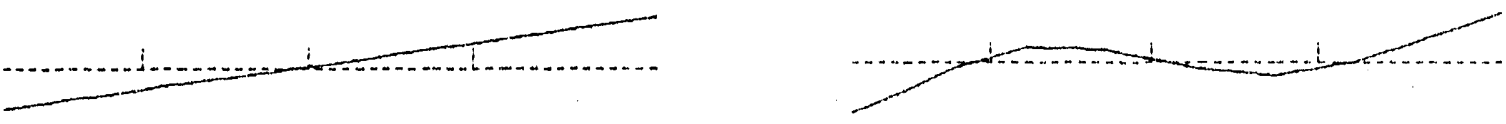

$15.4 \mathrm{HZ}$

$936.5 \mathrm{HZ}$

$142.6 \mathrm{HZ}$

$1125 \mathrm{HZ}$
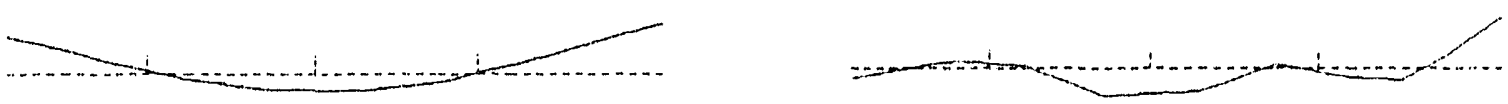

Fig. $5 a$. Section 4 
IN-PLANE MODES

$82.8 \mathrm{HZ}$

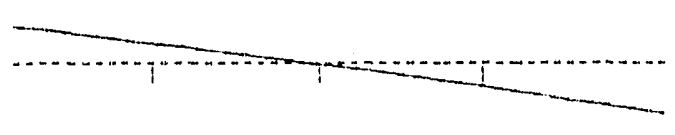

$99.4 \mathrm{HZ}$

$256.2 \mathrm{HZ}$

Fig. 5b. Section 4
$401.4 \mathrm{HZ}$

$1365 \mathrm{HZ}$

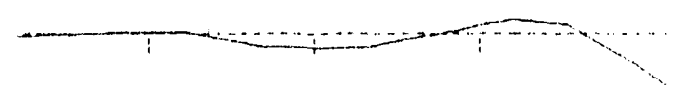

$1505 \mathrm{HZ}$

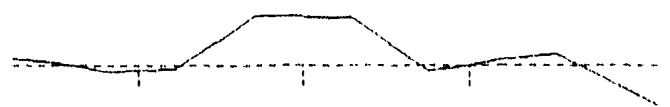




\section{OUT-OF-PLANE MODES}

$12.9 \mathrm{HZ}$

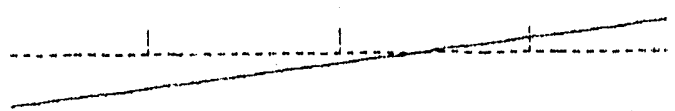

$581.9 \mathrm{HZ}$

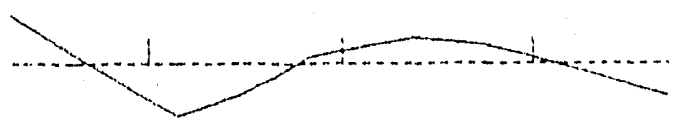

$1033 \mathrm{HZ}$

$16.65 \mathrm{HZ}$

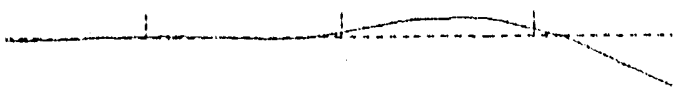

$1822 \mathrm{HZ}$

$119.8 \mathrm{~Hz}$

Fig. 6a. Saction 5 


\section{IN-PLANE MODES}

$83.3 \mathrm{HZ}$

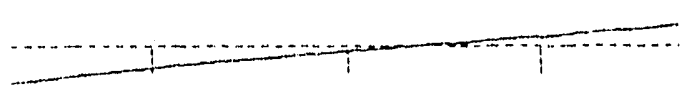

$110 \mathrm{HZ}$

$233 \mathrm{~Hz}$

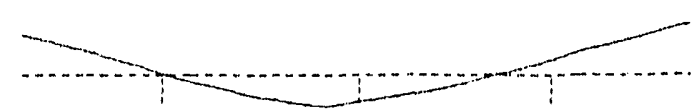

$849 \mathrm{HZ}$

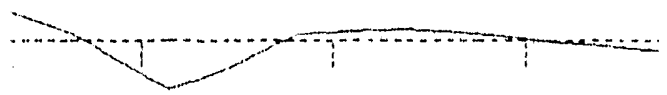

$1500 \mathrm{HZ}$

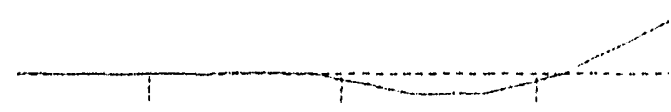

$2303 \mathrm{HZ}$

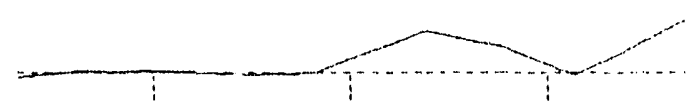

Fig. 6b. Section 5 


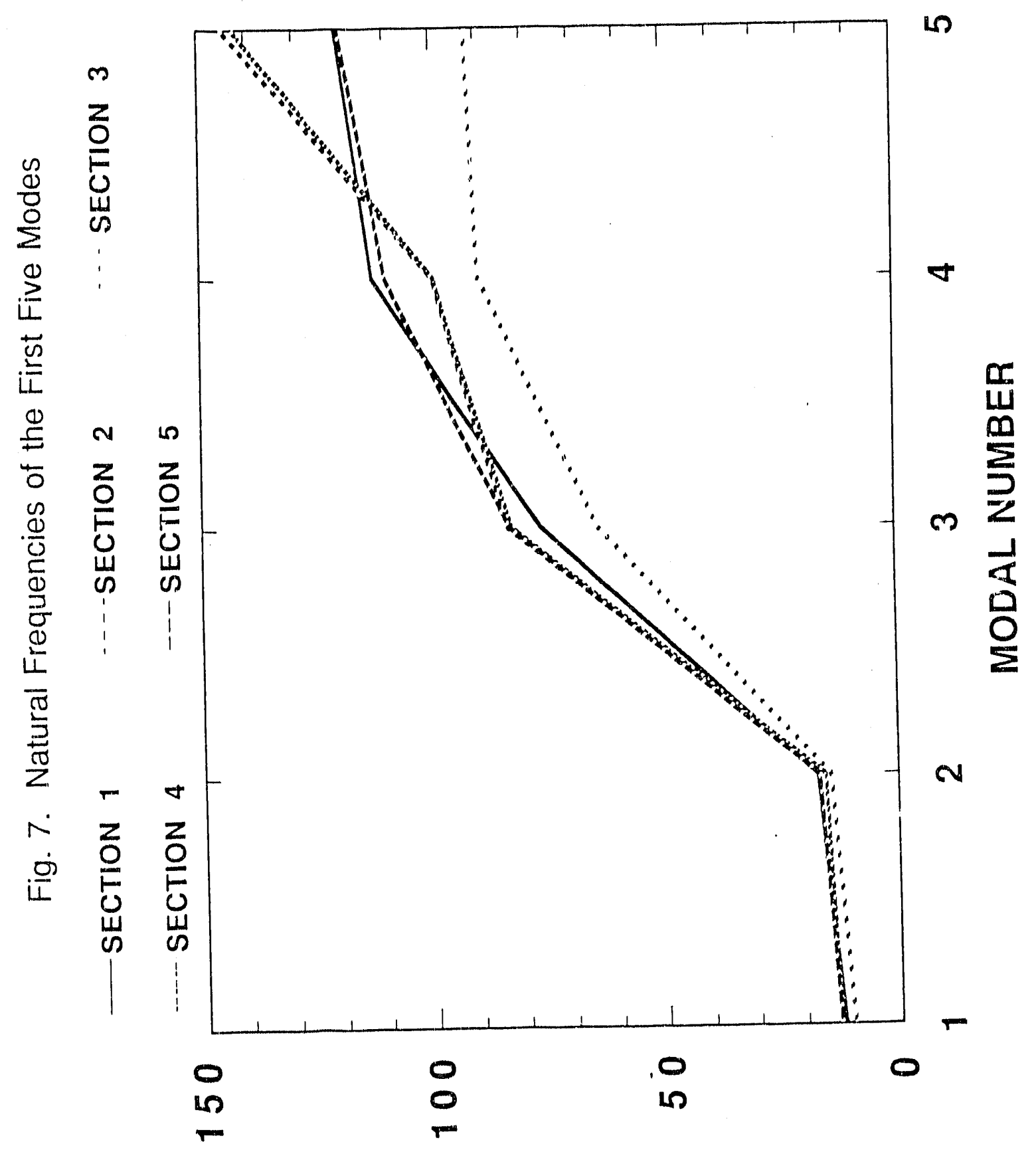

ZH ‘ $\lambda O N \exists \cap O \exists y \unlhd 7 \forall \forall \cap \perp \forall N$ 


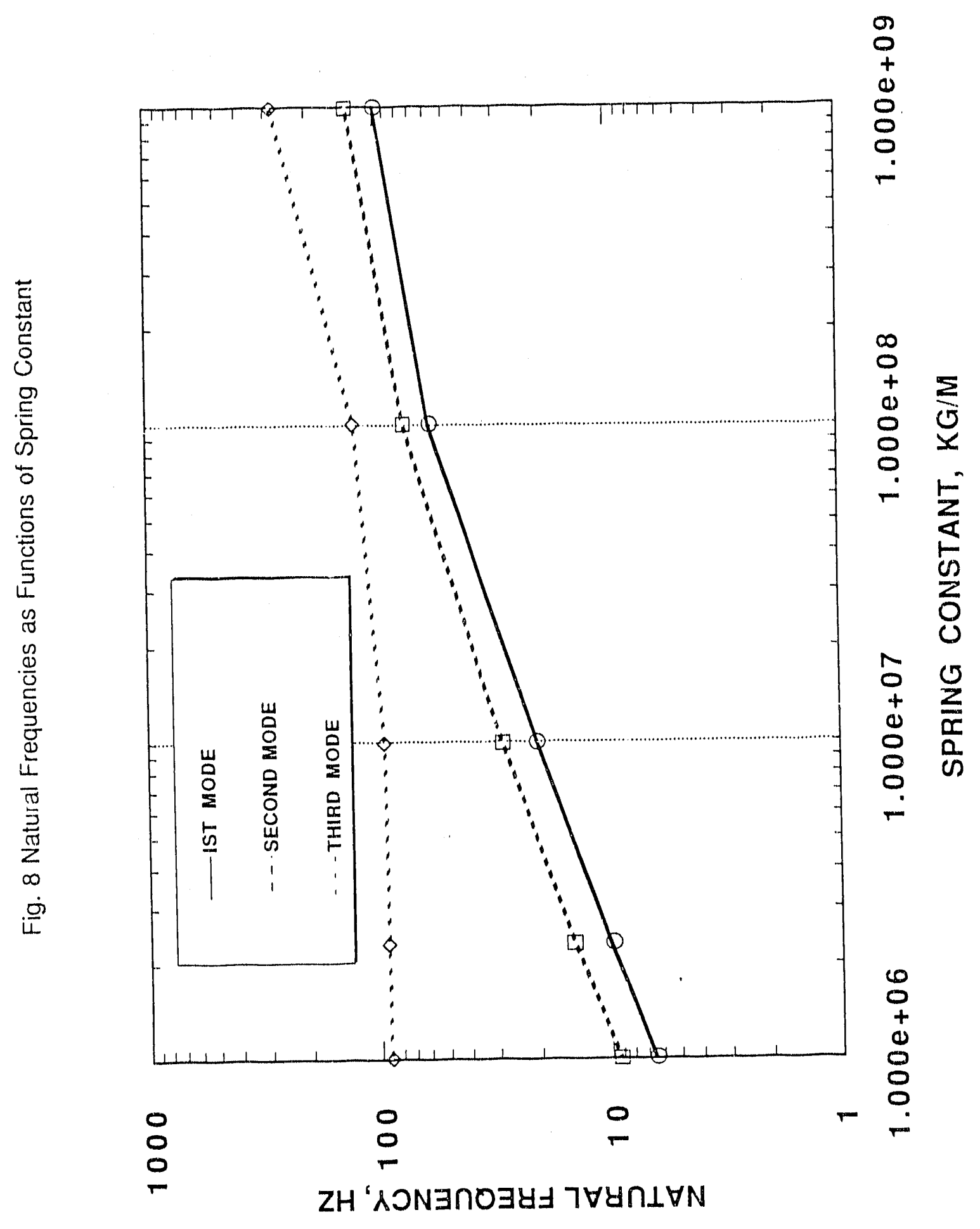




\section{APPENDIX}

Estimation of spring constants associated with pedestal supports -

Pedestal support between floor and jack-screw consists of $0.424 \mathrm{~m}$ long, $11.1 \mathrm{~cm}$ o.d. steel pipe, $6.42 \mathrm{~mm}$ thick:

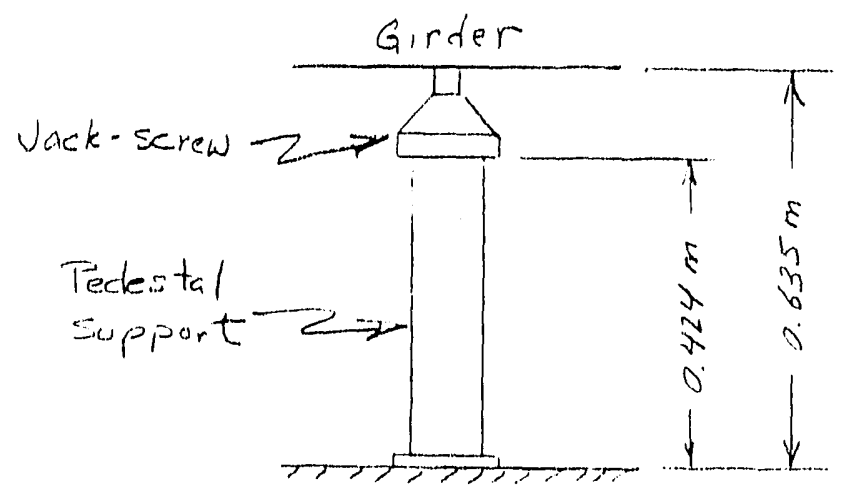

Assume the jack-screw is rigid and the elasticity is provided by the steel pedestal support.

\section{Vertical Mode}

The spring constant associated with axial displacement of the pedestal support (vertical or in-plane vibration) can be approximated as

$$
k_{V}=E A / L
$$

where,

$$
E=\text { Young's modulus, }
$$

$A=$ Cross-sectional area of pedestal support,

$L=$ Length of pedestal support.

Based on a length of $0.424 \mathrm{~m}, k_{V}=1.03 \times 10^{9} \mathrm{~N} / \mathrm{m}$; based on the total distance from floor to girder of $0.635 \mathrm{~m}, k_{v}=6.88 \times 10^{8} \mathrm{~N} / \mathrm{m}$.

\section{Horizontal Mode}

The spring constant associated with lateral bending of the pedestal support, as occurs in horizontal (out-of-plane) vibration, can be approximated as

$$
k_{H}=3 E I / L^{3}
$$

where, the pedestal support is assumed fixed at the base (attachment to 
the floor) and

$$
I=\text { Moment of inertia of the cross-section. }
$$

Based on a length of $0.424 \mathrm{~m}, \mathrm{k}_{H}=2.37 \times 10^{7} \mathrm{~N} / \mathrm{m}$; based on the total distance from floor to girder of $0.635 \mathrm{~m}, \mathrm{k}_{H}=7.06 \times 10^{6} \mathrm{~N} / \mathrm{m}$. 

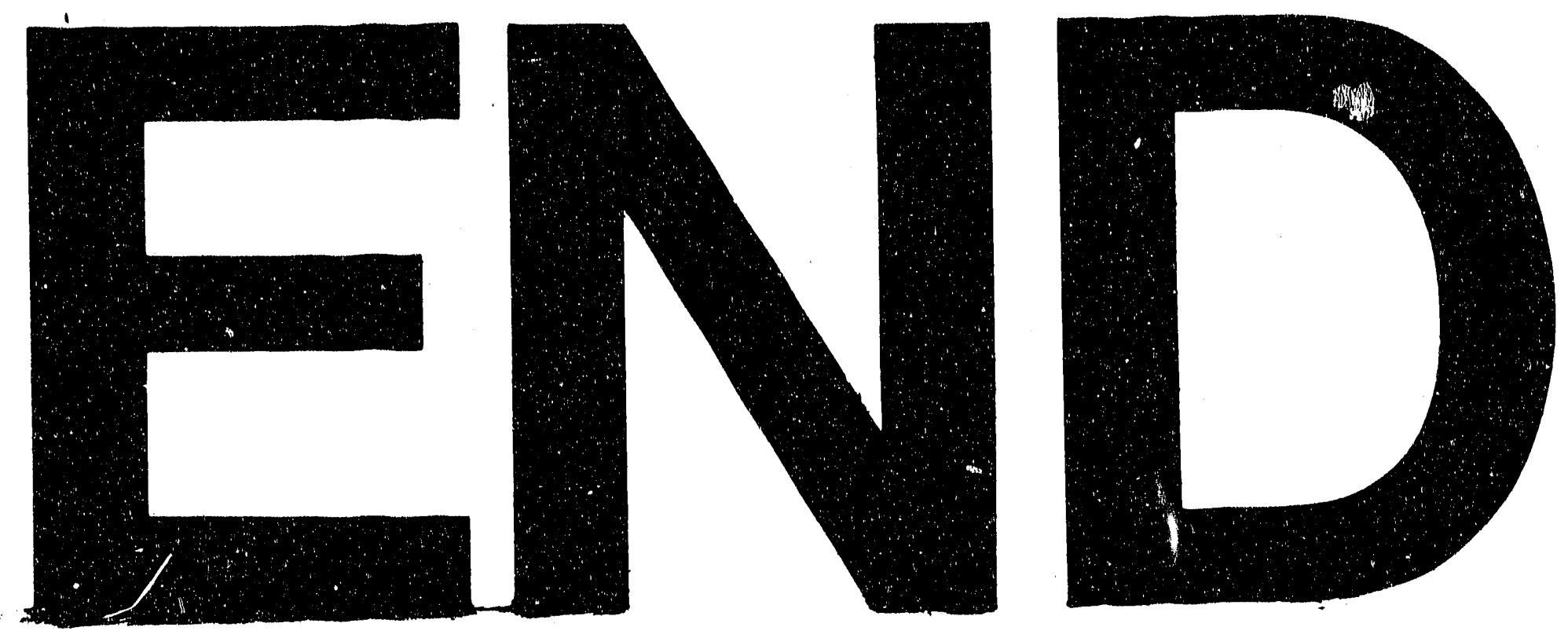

L. 2
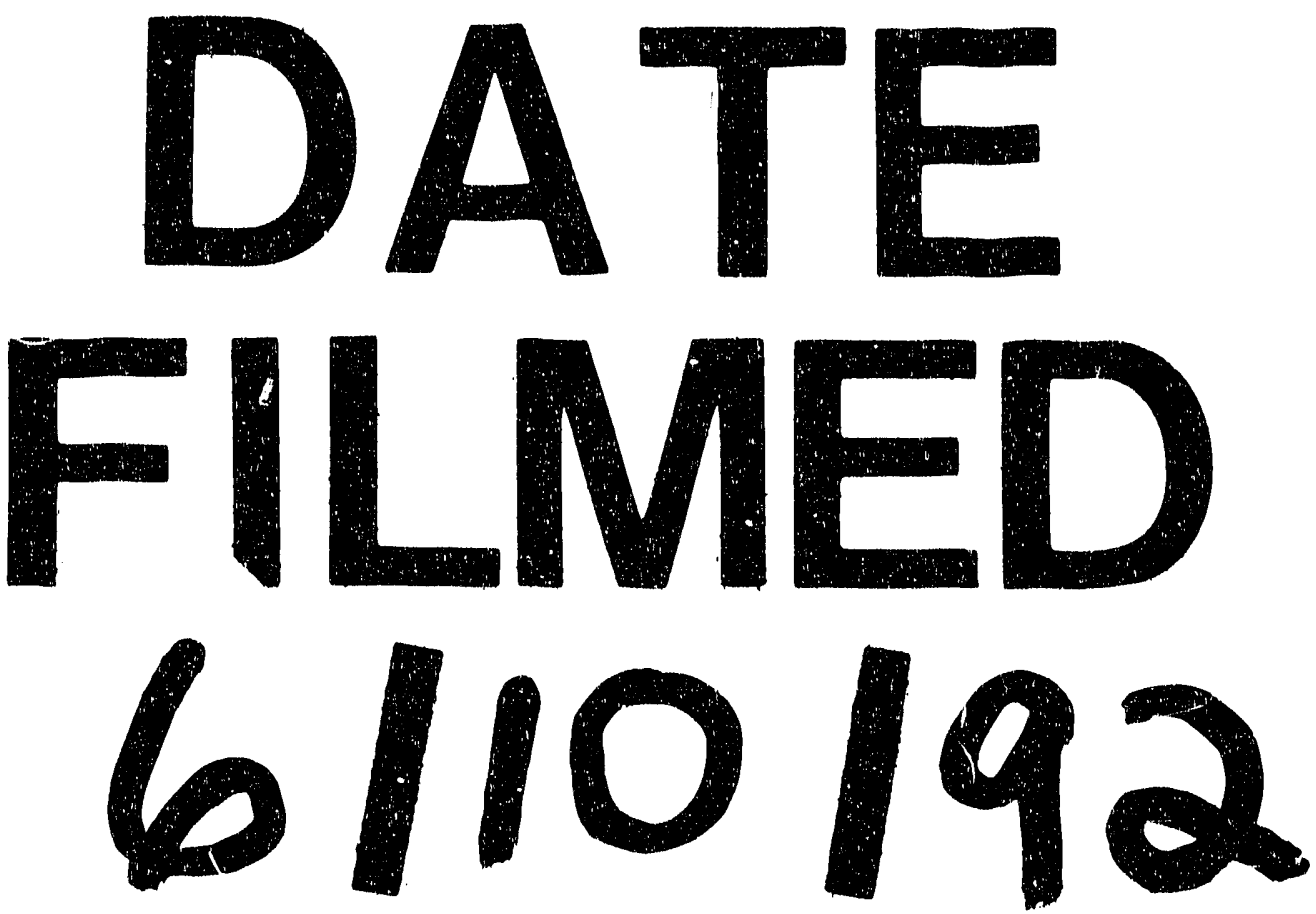
